\title{
Comparison of Fuel Properties between Diesel and Fatty Acid Methyl Ester
}

\author{
Chunhong Zhu ${ }^{\mathrm{a}}$, Jiangtong Song ${ }^{\mathrm{b}}{ }^{*}$ and $\mathrm{Jie}^{\mathrm{Li}}{ }^{\mathrm{c}}$ \\ School of Automobile Engineering, Beijing Polytechnic, Beijing 100176, China \\ azhuchunhong2009@126.com, btjsjt@eyou.com, 'Plijie1688@163.com
}

Keywords: diesel, biodiesel, fatty acid methyl ester, fuel properties.

\begin{abstract}
In order to optimize the application of biodiesel for diesel engines, the low-temperature fluidity, pulverization and evaporation, erosion capability and invariability of diesel and fatty acid methyl ester (FAME) were compared and analyzed. The cold filter plugging point, solidifying point, distillation temperature, flash point, kinematic viscosity, specific gravity, gelatin content, carbon residue, sculpture content, acidity, copper corrosion and ash tests were investigated according to the specifications given in the standards of China on certified machines.
\end{abstract}

\section{Introduction}

Diesel engines are efficient power machinery for automotive applications due to their better fuel economy compared to gasoline engines. However, stringent emission regulations and future depletion of petroleum reserves force us to explore new technologies to develop alternative fuel as well as reduce pollutant emissions [1].

Alternative fuels such as biodiesel and ethanol can satisfy the demand for renewable energy sources with low environmental impacts. While ethanol has been used as a total or partial substitute fuel for gasoline in countries like Brazil and USA, vegetable oil or animal fat derived biodiesel has largely grown as a substitute for diesel oil. Biodiesel has progressively been used to reduce diesel sulfur content [2].

Biodiesel is produced by transesterification of oil, where one mole of oil is chemically reacted with three moles of an alcohol in presence of a catalyst. In this reversible reaction, the glycerol moiety of the triglyceride molecule is replaced with an alkali radical of the alcohol used, giving alkyl based monoesters [3].

Biodiesel is now mainly being produced from soybean and rapeseed oils. Soybean oil is of primary interest as biodiesel source in the United States, while many European countries are concerned with rapeseed oil, and countries with tropical climate prefer to utilize coconut oil or palm oil. However, any vegetable oil-corn, cottonseed, peanut, sunflower, safflower, coconut or palm-could be used to produce biodiesel [4]. Furthermore, other sources of biodiesel studied include animal fats and used or waste cooking oils. Researchers are also developing algae that produce oils, which can be converted to biodiesel.

Although biodiesel has many advantages when it comes to fuel properties, it still has several properties that need to be improved, such as its lower calorific value, lower horsepower output, and its comparatively higher emission of nitrogen oxides [5]. Fuel characterization data show some similarities and differences between biodiesel and petro diesel fuels. Sulfur content of petro diesel is 20-50 times those of biodiesels [4]. Several municipalities are considering mandating the use of low levels of biodiesel in diesel fuel on the basis of several studies which have found HC and particulate matter (PM) benefits from the use of biodiesel [6].

Ayman [4] investigated the higher heating values of biodiesel from soybean and rapeseed and palm oil. The higher heating values (HHVs) of biodiesels were relatively high. The HHVs of biodiesels (39-41 MJ/kg) were slightly lower than that of gasoline (46 MJ/kg), petro diesel (43 MJ/kg) or petroleum (42 MJ/kg), but higher than coal (32-37 MJ/kg). 
In order to compare and analyses the low-temperature fluidity, pulverization and evaporation, erosion capability and invariability of diesel and fatty acid methyl ester (FAME). The cold filter plugging point, solidifying point, distillation temperature, flash point, kinematic viscosity, specific gravity, gelatin content, carbon residue, sculpture content, acidity, copper corrosion and ash tests were investigated according to the specifications given in the standards of China on certified machines in this paper.

\section{Test procedure}

In order to compare and analyses the low-temperature fluidity, according to the standard SH/T 0248 and GB/T 510 of China, the cold filter plugging point and solidifying point of diesel and FAME were tested. In order to compare and analyses the pulverization and evaporation, according to the standard GB/T 6536, GB/T 261 and GB/T 265, the distillation temperature at 50\%, 90\% and 95\%, flash point, kinematic viscosity at $20^{\circ} \mathrm{C}$ and $40^{\circ} \mathrm{C}$ of diesel and FAME were tested. In order to compare and analyses the erosion capability, according to the standard GB/T 380 and GB/T 258, the sculpture content and acidity of diesel and FAME were tested. In order to compare and analyses the invariability, according to the standard SH/T 0175 and GB/T 268, the gelatin content and carbon residue of diesel and FAME were tested.

\section{Results and discussion}

Low-temperature fluidity. The variation in cold filter plugging point and solidifying point between diesel and FAME is presented in Fig.1. Cold filter plugging point (CFPP) is the lowest temperature, at which a given volume of diesel type of fuel still passes through a standardized filtration device in a specified time when cooled under certain conditions. This is important as in cold temperate countries and a high cold filter plugging point will clog up vehicle engines more easily. Compare with diesel, the cold filter plugging point of FAME decreases while the solidifying point increases.

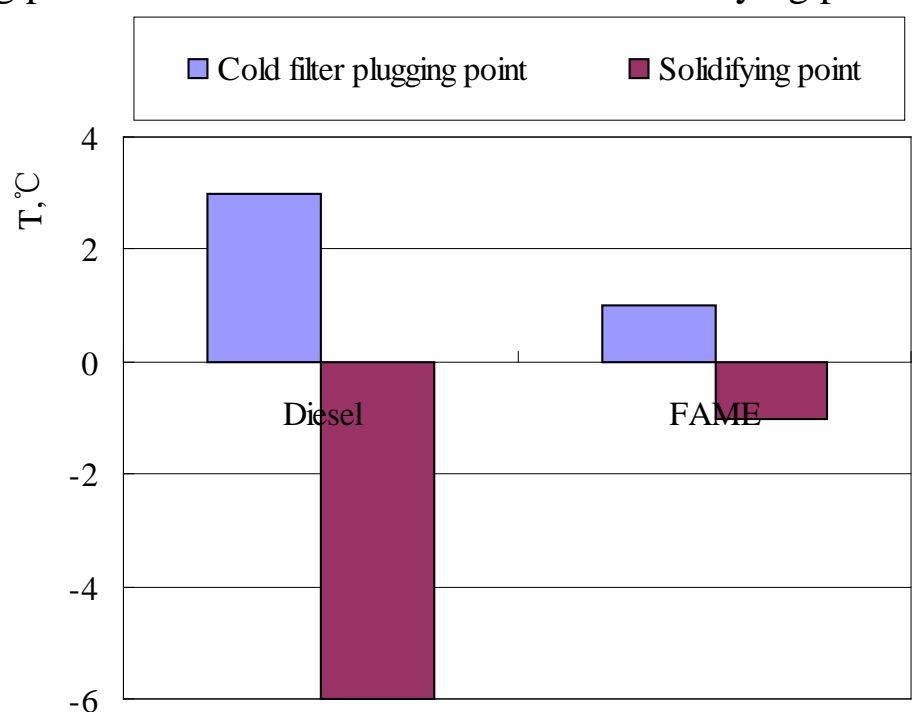

Fig.1 Comparison of cold filter plugging point and solidifying point between diesel and FAME

Pulverization and evaporation. The variation in distillation temperature between diesel and FAME is presented in Fig.2. Compare with diesel, the distillation temperature at $50 \%$ of FAME increases while at $90 \%$ and $95 \%$ decrease slightly.

Flash point is the temperature at which the fuel becomes a mixture that will ignite when exposed to a spark or flame. The flash point of the fuel gives the tendency of a sample to spontaneously form a flammable mixture. It is an important parameter related to the ignition properties of any fuel and its safety during handling [3]. The variation in flash point between diesel and FAME is presented in Fig.3. Compare with diesel, the flash point of FAME increases. 
Viscosity is an important property of any fuel as it is an indication of the ability of a material to flow. The kinematic viscosity is a basic fuel specification for injectors used in diesel engines. Viscosity is an important fuel parameter because it affects the atomization quality, size of drop and penetration. The variation in kinematic viscosity between diesel and FAME is presented in Fig.3. Compare with diesel, the kinematic viscosity at $20^{\circ} \mathrm{C}$ and $40^{\circ} \mathrm{C}$ of FAME increases.

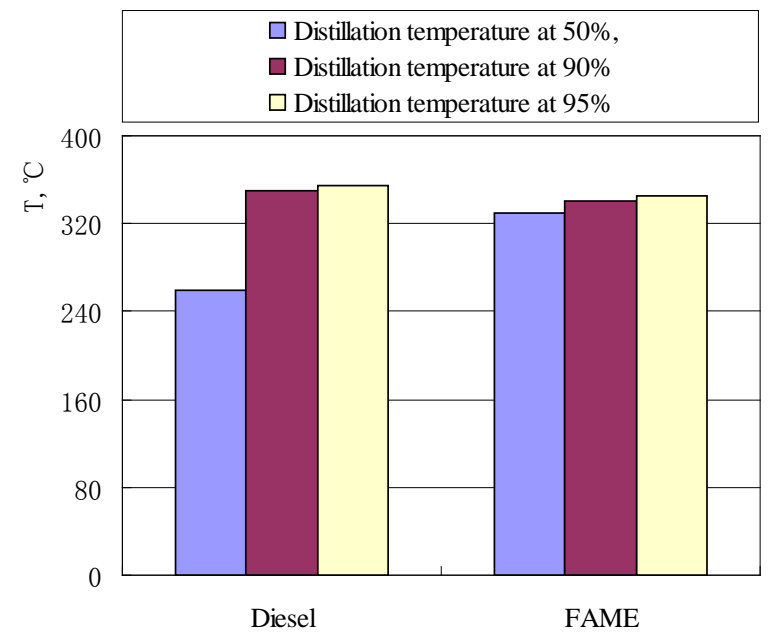

Fig.2 Comparison of distillation temperature between diesel and FAME

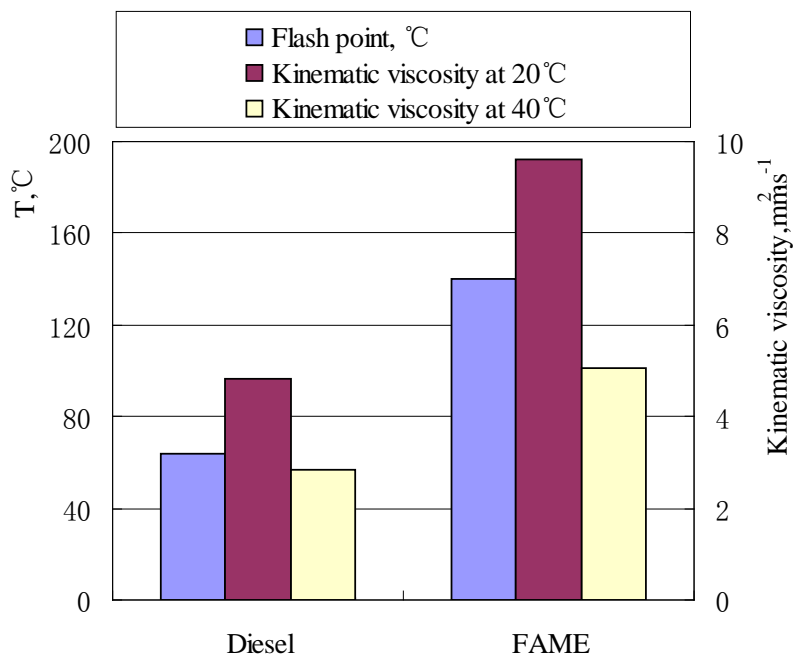

Fig.3 Comparison of flash point and kinematic viscosity between diesel and FAME

Erosion capability. In diesel fuels, a portion of the sulfur content combines chemically with water during the combustion process to form sulfurous and sulfuric acid. The result is corrosive wear that eventually leads to component failure. The variation in sulfur content between diesel and FAME is presented in Fig.4. Compare with diesel, the sulfur content of FAME decreases sharply.

The acidity is a measure of the amount of acidic substances in a fuel under the conditions specified. The acidity is an important factor that determines the quality of fuel. It reflects on the storage characteristics and corrosion properties of any fuel. It also can provide an indication of the level of lubricant degradation while the fuel is in service. The variation in acidity between diesel and FAME is presented in Fig.4. Compare with diesel, the acidity of FAME increases sharply.

Invariability. Carbon residue is an indicator of not only the amount of the material left after vaporation and pyrolysis but also the amount of glycerides (free glycerol, partially reacted/un-reacted glycerides) and other residues remaining in the biodiesel product (free fatty acids and catalyst residue). The variation in gelatine content and carbon residue between diesel and FAME is presented in Fig.5. Compare with diesel, the gelatine content and carbon residue of FAME increases sharply. 


\section{Conclusions}

According to the standards of China, the main properties of diesel and fatty acid methyl ester (FAME) were compared and analyzed. Experiment result shows that compared with diesel fuel, the cold filter plugging point of FAME decreases while the solidifying point increases, the distillation temperature at 50\%, flash point and kinematic viscosity of FAME increases while distillation temperature at $90 \%$ and 95\% decrease slightly, the sulfur content of FAME decreases sharply while the acidity of FAME increases sharply, the gelatin content and carbon residue of FAME increases sharply.

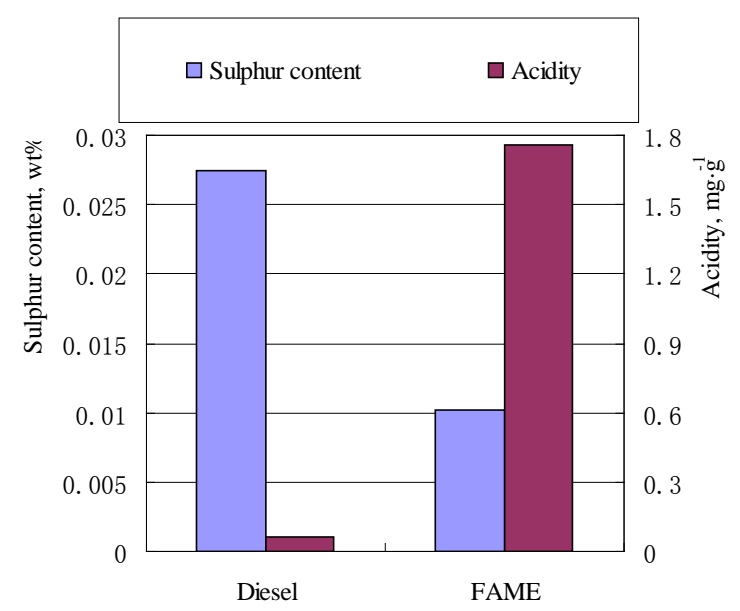

Fig.4 Comparison of sculpture content and acidity between diesel and FAME

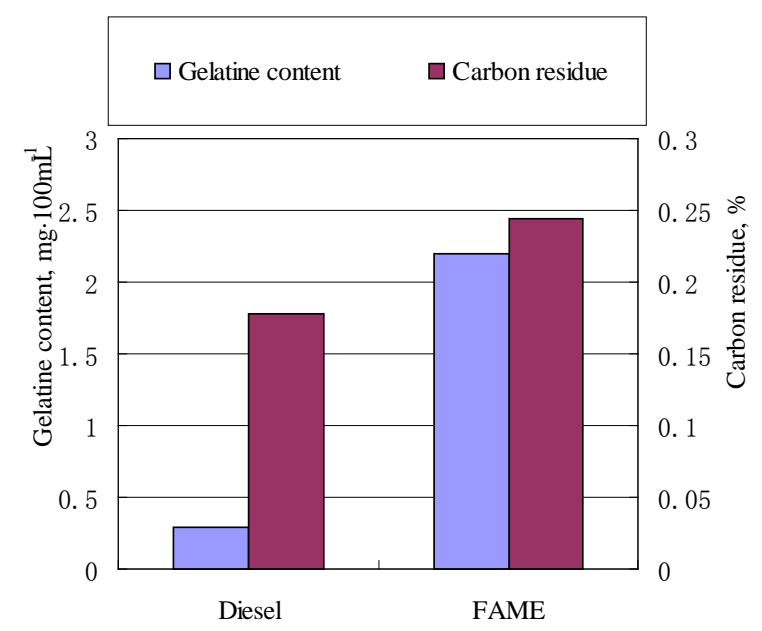

Fig.5 Comparison of gelatin content and carbon residue between diesel and FAME

\section{Acknowledgement}

This research was supported by the Scientific Research Common Program of Beijing Municipal Commission of Education (KM201410858004).

\section{References}

[1] Fujia Wu, Jianxin Wang, Wenmiao Chen, et al. A study on emission performance of a diesel engine fueled with five typical methyl ester biodiesels. Atmospheric Environment. 43 (2009) p. 1481-1485.

[2] Mário Luciano Randazzo, José Ricardo Sodré. Cold start and fuel consumption of a vehicle fuelled with blends of diesel oil-soybean biodiesel-ethanol. Fuel. 90 (2011) p. 3291-3294.

[3] Akanksha Kanitkar, Sundar Bala Subramanian, Marybeth Lima, et al. A critical comparison of methyl and ethyl esters production from soybean and rice bran oil in the presence of microwaves. Bio resource Technology. 102 (2011) p. 7896-7902.

[4] Demirbas Ayhan. Importance of biodiesel as transportation fuel. Energy Policy. 35 (2007) p. 4661-4670.

[5] B. Gokalp, E. Buyukkaya, H. S. Soyhan. Performance and emissions of a diesel tractor engine fueled with marine diesel and soybean methyl ester. Biomass and Bioenergy. 35(2011) p. 3575-3583.

[6] Roberto G. Pereira, Cesar D. Oliveira, Jorge L. Oliveira, et al. Exhaust emissions and electric energy generation in a stationary engine using blends of diesel and soybean biodiesel. Renewable Energy. 32 (2007) p. 2453-2460. 
[7] Michal Černoch, Martin Hájek, František Skopal. Relationships among flash point, carbon residue, viscosity and some impurities in biodiesel after ethanolysis of rapeseed oil. Bioresource Technology. 101 (2010) p. 7397-7401. 